\title{
Contribuições da educação ambiental para a cidadania
}

Elisa Luzia Costa de Santana ${ }^{1}$, Tatiana Polliana Pinto de Lima ${ }^{2}$

\section{Resumo}

O presente texto apresenta um dos capítulos da dissertação de Mestrado em Desenvolvimento Regional e Meio Ambiente, cujo estudo objetivou analisar a prática docente em Educação Ambiental (EA) nos anos finais da Educação de Jovens e Adultos (EJA). A pesquisa foi desenvolvida a partir de uma abordagem qualitativa, por meio da realização de entrevistas com docentes na Escola Classe I - Centro Educacional Carneiro Ribeiro (CECR) e da leitura do Projeto Político-Pedagógico (PPP) do referido centro. O resultado desse estudo foi contribuir com a inclusão de um anexo ao PPP do CECR de Salvador/BA, visando à inserção da EA e Saúde nas disciplinas do currículo da EJA, além de apresentar como proposta a implantação de um núcleo ou observatório de EA no CECR.

\section{Palavras-chave}

Degradação ambiental. Prática docente. Formação cidadã.

\footnotetext{
${ }^{1}$ Mestra em Desenvolvimento Regional e Meio Ambiente pela Universidade Federal do Recôncavo da Bahia, Brasil; professora da rede estadual de educação da Bahia, Brasil. E-mail: elisalimonetes @ gmail.com.

${ }^{2}$ Doutora em Educação pela Universidade da Bahia, Brasil; professora adjunta no Centro de Cultura, Linguagens e Tecnologias Aplicadas da Universidade Federal do Recôncavo da Bahia, Brasil. E-mail: tatyalima@yahoo.com.
} 


\title{
Contributions of environmental education to citizenship
}

Elisa Luzia Costa de Santana ${ }^{3}$, Tatiana Polliana Pinto de Lima ${ }^{4}$

\begin{abstract}
This text presents one of the chapters of the master degree dissertation in regional development and environment which study aimed to analyze the teaching practice in Environmental Education (EE) in the final years of the Education of Young and Adults (EYA). For that, the research was developed from a qualitative approach that happened in two moments: interviews with the teachers in the Class I School Carneiro Ribeiro Educational Center (CECR) and the reading of the Politic-Pedagogical Project (PPP) of said Center. The result of this study was to contribute through the inclusion of an annex to the PPP of CECR Salvador, State of Bahia, to insert EE and Health in the subjects of the EYA curriculum and presented as proposal the implementation of the environmental education observatory nucleus or referred center.
\end{abstract}

\section{Keywords}

Environmental degradation. Teaching practice. Citizen training.

\footnotetext{
${ }^{3}$ Master in Regional Development and Environment, Federal University of Recôncavo da Bahia, State of Bahia, Brazil; teacher at the state education network in Bahia, Brazil. E-mail: elisalimonetes@gmail.com.

${ }^{4} \mathrm{PhD}$ in Education, University of Bahia, State of Bahia, Brazil; adjunct professor at the Center for Culture, Languages and Applied Technologies at the Federal University of Recôncavo da Bahia, State of Bahia, Brazil. E-mail: tatyalima@yahoo.com.
} 


\section{Introdução}

Diante dos problemas socioambientais enfrentados na atualidade, como urbanização descontrolada, saneamento básico precário (armazenamento de água por conta de escassez ou falta de tanque), existência de esgotos expostos, acúmulo de lixo nas ruas e a expansão das doenças, a escola, como instituição formadora de cidadãos, vem sendo pressionada a desenvolver novas funções sociais e práticas pedagógicas voltadas para a formação de valores, deveres e direitos relacionados à preservação ambiental, devendo apresentar aos alunos as causas e consequências dos referidos problemas.

Este relato de experiência apresenta parte de uma pesquisa de mestrado em Desenvolvimento Regional e Meio Ambiente, cujo estudo objetivou analisar a prática docente em EA (EA) nos anos finais da Educação de Jovens e Adultos (EJA) da Escola Classe I Centro Educacional Carneiro Ribeiro (CECR), localizada em Salvador, Bahia.

A pesquisa se baseou na seguinte pergunta: como os professores vêm trabalhando a EA com os estudantes do $6^{\circ}$ ao $9^{\circ}$ ano da EJA?

O cuidado com o meio ambiente tornou-se uma exigência das sociedades sustentáveis e a escola tornou-se um espaço de percepção da diversidade do ambiente. Assim, este relato de experiência relaciona-se ao aperfeiçoamento da prática docente em EA e a formação para o exercício da cidadania em prol da superação da degradação do meio ambiente influenciada por aspectos socioeconômicos, políticos, culturais e ambientais, conforme consta no referencial teórico desse trabalho, significando grande relevância científica. Acredita-se que a importância social dessa temática justifica a defesa de uma prática docente em EA que promova, na comunidade escolar, a mudança para um novo olhar sobre a inclusão da EA na EJA, na Escola Classe I.

Assim, é necessária uma prática docente em EA que possibilite aos estudantes o saber no seu contexto, incentive a produção de conhecimentos em EA e participação de toda comunidade escolar no planejamento das políticas educacionais.

Dessa maneira, a EJA foi escolhida no referido estudo porque os alunos do $6^{\circ}$ ao $9^{\circ}$ anos da Escola Classe I fazem parte de comunidades pertencentes à área do bairro Liberdade. São comunidades penalizadas por problemas socioambientais relacionados à infraestrutura mencionados por alguns autores como Serpa e Santos (2000), que citam Jorge Amado ao afirmarem que apesar das glórias ocorridas na área da Liberdade durante a Independência da Bahia, seus moradores amargam o descaso do poder público: 
Se quereis a qualidade deste bairro, destes casarões infames, das moradias desgraçadas, eu vos direi apenas: resistência. Resistência à fome e à enfermidade, ao trabalho mal remunerado, às mortes dos filhos, ao hospital, à desgraça da vida. Resistência. A resistência do povo é além dos limites. Apesar de tudo ele sobrevive. E aos seus bairros imundos esses nomes de esperança que são como bandeiras que ele levanta em suas mãos magras, mas ainda assim poderosas. Estrada da Liberdade! (AMADO, 1974 apud SERPA; SANTOS, 2000, p. 45).

Entretanto, mesmo vivenciando os problemas acima citados, muitos alunos apresentam dificuldades em compreender a relação entre a EA e a saúde de forma contextualizada e, consequentemente, as interferências dos problemas ambientais no surgimento das doenças.

Com relação aos métodos e às técnicas da pesquisa, optou-se pela pesquisa tipo qualitativa, o estudo de caso como método de pesquisa, a entrevista semiestruturada e, como complemento, a pesquisa documental baseada no PPP da Escola Classe I, além de apresentar a caracterização do lócus da pesquisa, a seleção dos sujeitos e os aspectos éticos na pesquisa.

Na seção resultados e discussão, foram apresentados os dados coletados por meio da pesquisa documental apoiada no PPP da escola em estudo e de entrevistas com os professores que permitiram a coleta de dados sobre: atualização e prática docente em EA; sugestões sobre a interligação entre os temas ambientais e os conteúdos da EJA; EA no currículo da EJA e no PPP da escola; relação entre os problemas ambientais e a saúde; percepções docentes da organização da EA; visão do homem e influências teóricas implícitas no currículo, metodologia, prática docente em EA e saberes necessários a essa prática.

A preservação ambiental é um dever de todos e está intimamente relacionada com o direito à qualidade de vida e, consequentemente com a saúde. Quando a educação também está voltada para o exercício da cidadania, a participação dos indivíduos ajuda na luta pelo direito à saúde, aqui entendida em seu caráter amplo, ou seja, acesso à educação, atendimento médico, saneamento básico, lazer, emprego, moradia etc.

Nesse sentido, Valla e Stotz (1994), considerando a educação como um dos instrumentos de cidadania e participação popular em prol da saúde, afirmam que a participação popular representa uma força social imprescindível para fazer sair do papel as conquistas e impulsionar as mudanças necessárias.

Nessa perspectiva, e, de acordo com os objetivos anteriormente citados, as considerações finais deste relato representam um chamado coletivo para que os professores dos anos finais do ensino fundamental da EJA discutam e incorporem, na prática docente da 
$\mathrm{EA}^{5}$, a formação cidadã para uma nova ética, participação social quanto aos problemas socioambientais de modo que sejam entendidos em seu contexto sócio histórico, relacionando-os com a saúde e qualidade de vida.

Nesse contexto, o objetivo geral que deu origem a este relato de experiência foi a prática docente em EA desenvolvida no CECR, Escola Classe I, com os estudantes do $6^{\text {a }}$ ao $9^{\text {a }}$ ano da EJS. Assim, foram elencados os seguintes objetivos específicos: a) acrescentar um anexo ao Projeto Político-Pedagógico (PPP) do CECR/Escola Classe I; b) sugerir no PPP a implantação de um núcleo ou observatório de EA no CECR/Escola Parque para o aperfeiçoamento dos docentes; c) socialização de conhecimentos e experiências entre a escola e a comunidade escolar.

\section{Desenvolvimento}

A EA é uma área transdisciplinar cujo maior desafio é estimular a proteção ao meio ambiente a partir de uma perspectiva política de luta pelo exercício da cidadania dos grupos excluídos e socialmente oprimidos em prol da equidade social, de modo que esses grupos sejam capazes de refletir sobre sua relação com o ambiente físico-natural e lutar pelo direito à qualidade de vida. Diante disso, destaca-se a seguir a relação entre a EA e a Cidadania.

\section{Educação ambiental e cidadania}

A EA é auxiliada pela interdisciplinaridade quanto ao desenvolvimento dos valores e sensibilização e consciência crítica diante dos problemas ambientais, pois quando a proposta educacional é coerente com a concepção em conjunto e comprometida com a formação da cidadania evita ideologias de manipulação do indivíduo. Daí a importância do trabalho integrado entre as disciplinas e a reflexão sobre os vários caminhos do conhecimento, tão necessários à visão do meio ambiente de forma completa, ou seja, que abranja os aspectos sociais, econômicos, políticos, culturais, históricos e éticos.

Devido a sua complexidade, o trabalho da EA deve ser intercalado entre os diversos saberes. Segundo Brugger (1994), devido ao seu caráter transdisciplinar, a superação dos problemas relacionados ao meio ambiente deve ser pensada em seu caráter social e não

\footnotetext{
${ }^{5}$ Vale salientar que o tema deste relato reflete a busca por uma prática docente da EA trabalhada de forma reflexiva e vinculada ao contexto sociocultural do aluno, a fim de desenvolver a consciência crítica quanto às mudanças no meio natural em nível local e global que, consequentemente, afetam o planeta e o homem.
} 
apenas de forma técnica ou natural privilegiando a integração do conhecimento para uma visão crítica da realidade.

$\mathrm{O}$ olhar da EA como uma área específica e isolada distorce o seu aspecto transdisciplinar, conforme se percebe na afirmação da Organização das Nações Unidas para Educação, Ciência e Cultura (UNESCO, 2005): "EA é uma disciplina bem estabelecida e que enfatiza a relação dos homens com o ambiente natural, as formas de conservá-lo, preservá-lo e de administrar seus recursos adequadamente". Esse conceito é contraditório, pois considerar essa área do conhecimento como uma disciplina enseja a dicotomia da relação entre teoria, princípios da EA e prática docente.

Nesse contexto, percebe-se que o caráter integrador do meio ambiente não se restringe apenas ao conhecimento teórico, pois somente ele, sem a ação e o entendimento do contexto, leva a uma postura antropocêntrica (o homem como ser superior e externo ao meio ambiente).

Para Grynszpan et al. (2014), a EA busca contribuir para uma visão humanística, uma postura ética e cidadã, com base no empoderamento individual e coletivo, visto que a educação é capaz de incluir valores, capacidades, conhecimentos, responsabilidades e aspectos que promovam o progresso das relações éticas entre as pessoas, seres vivos. Essa postura cidadã implica no exercício de direitos e deveres civis, políticos e sociais do indivíduo perante o Estado e a sociedade. Segundo Coure (2002, p. 11), “cidadania é o próprio direito à vida no sentido pleno. Um direito que precisa ser construído coletivamente não só em termo de atendimento às necessidades básicas, mas de acesso a todos os níveis da existência".

Ao comprometer-se com a formação cidadã, a EA contribui para a participação da sociedade no exercício de seus deveres com a preservação ambiental, assim como enseja a luta coletiva dos cidadãos pelos direitos de acesso aos recursos naturais e à qualidade de vida exercendo dessa forma a cidadania ambiental que, segundo Waldman (2003) pode ser considerada uma "responsabilidade ambiental" participativa que pressupõe uma relação mais harmoniosa com o meio ambiente.

Nesse contexto, compreende-se que o desenvolvimento da cidadania ambiental implica no trabalho interdisciplinar e na participação política de todos da comunidade escolar, local e global, envolvendo não somente os professores e alunos na construção de conhecimento diversificado e contextualizado sobre a problemática socioambiental e sensibilização quanto aos valores indispensáveis para a formação da cidadania.

Segundo Jacobi (2003), a EA como formação e exercício de cidadania considera uma relação do homem com a natureza baseada numa nova ética, valores morais e visão do mundo e dos homens. Com isso, percebe-se que a formação cidadã está relacionada com a EA no 
sentido da busca pela preservação ambiental por meio da participação coletiva dos cidadãos nas ações que dizem respeito ao meio ambiente e comprometimento com as questões sociais a fim de amenizar os problemas ambientais as injustiças entre os indivíduos.

$\mathrm{Na}$ escola, as questões ambientais são trabalhadas por meio da EA, contribuindo na construção de relações e intercâmbios entre as diversas disciplinas. Para Phillip e Pelicioni (2014), essas relações e intercâmbios dependem de orientação, preparo e, principalmente, motivação dos docentes em participarem desse processo através da capacitação docente e do trabalho interdisciplinar entre EA e as demais áreas do conhecimento.

A escola pública é um dos espaços para formação dos futuros cidadãos para o respeito com o meio ambiente e para melhorar a qualidade de vida, mas para isso é preciso delimitar os objetivos e despertar no educando o interesse pelo meio ambiente, levando-o a perceber os problemas ambientais cotidianos, pois a responsabilidades com o meio ambiente e o contexto social devem ser entendidos a partir de novos olhares para esses problemas. Por isso, se faz necessária uma educação crítica. Neste sentido, a tendência crítico-social dos conteúdos concebe os problemas ambientais associados aos conflitos sociais, problematizando os contextos societários em sua interface com a natureza.

A referida tendência educacional assemelha-se à Teoria da Complexidade defendida por Edgar Morin (2011), pois os problemas ambientais vistos por meio dessa teoria têm origem nas relações sociais, nos modelos de sociedade e nas relações de produção baseadas no lucro. Com isso, o autor admite a necessidade de uma mudança múltipla que transforme a teoria, as relações sociopolíticas, a ética e os valores culturais.

Segundo Carvalho (2012, p. 125), "a educação ambiental crítica seria aquela capaz de transitar entre múltiplos saberes: científicos, populares e tradicionais, alargando nossa visão de ambiente e captando múltiplos sentidos que os grupos sociais lhe atribuem". Diante disso, nos anos finais do ensino fundamental, os professores, como mediadores do conhecimento, já podem contribuir com o aprendizado sobre o meio ambiente, despertando no aluno o respeito pela natureza, desenvolvendo neles habilidades de observação, crítica, criação, comparação, reelaboração e análise por meio do trabalho interdisciplinar.

Para tanto, cabe ao professor inovar as aulas, desenvolvendo projetos pedagógicos que aproximem o conteúdo ao contexto e às vivências dos alunos, principalmente na EA que, segundo Carvalho (2012), desperta enorme expectativa renovadora do sistema de ensino, da organização e dos conteúdos escolares, convidando a uma revisão da instituição e do cotidiano escolar mediante os atributos da transversalidade e da interdisciplinaridade. 
A escola é um dos espaços coletivos para o enfrentamento dos conflitos ambientais por meio do exercício da cidadania. Com isso, sua prática pedagógica deve ser baseada na reflexão sobre se a concepção e as opções político-pedagógicas de EA adotadas influenciam na participação coletiva ou não quanto ao destino dos recursos ambientais. Essa reflexão é enriquecida por meio do diálogo como um encontro que solidariza o agir e o refletir, conforme defende FREIRE (1987).

As reflexões e ações coletivas em prol do meio ambiente permitem a percepção da necessidade de uma relação humanizada com a natureza, principalmente nos centros urbanos onde as ações atópicas alimentadas pela busca do lucro e atendimento das necessidades humanas podem prejudicá-la. Nesse sentido, Pedrini (2012), chama atenção para o estilo de vida nas grandes cidades, que aliado a um forte apelo de propaganda, cria nas pessoas uma necessidade de consumo intensivo acelerando o processo de degradação ambiental.

Layrargues, Loureiro e Castro (2009) abordam a possibilidade de a EA poder contribuir para manter ou transformar a realidade social assimétrica e defendem a necessidade de que a EA seja em prol de melhorias, tanto ambientais como sociais. Para os eles, a EA exerce função moral de socialização humana com a natureza e a função ideológica de reprodução das condições sociais. A questão é se a função ideológica de reprodução das condições sociais será utilizada na manutenção ou na transformação social em busca do bem comum.

Os referidos autores chamam atenção quanto à exclusão, desigualdade e autoritarismo, o que deixa os brasileiros longe de atingirem a cidadania plena, pois as decisões que afetam a coletividade sempre estiveram circunscritas a uma minoria que, historicamente, vem influenciando os rumos do país. Esses mesmos autores citam o Brasil como um dos países mais desiguais do mundo e destacam que a EA não só poderia como deveria ser praticada com compromisso "social”, pois com ela é possível contribuir com a mudança do quadro das desigualdades no país e no mundo.

Nesse sentido, Layrargues, Loureiro e Castro (2009) defendem que para o desenvolvimento de uma EA capaz de estimular o exercício da cidadania é indispensável a atuação dos grupos sociais, especialmente dos excluídos da decisão do destino dos recursos da natureza. É preciso também o entendimento das abordagens político-ideológicas e estratégias que produzem e reproduzem as desigualdades, estimulando a reflexão coletiva nas discussões ambientais sobre as contradições e a assimetria no acesso aos direitos e de proteção contra riscos ambientais. Assim, os autores definem a EA crítica como um processo educativo eminentemente político, que visa ao desenvolvimento, nos educandos, de uma consciência 
crítica acerca das instituições, atores e fatores sociais geradores dos riscos e respectivos conflitos socioambientais.

Diante da busca pelos cidadãos, conjuntamente com a sociedade e o Estado, de soluções para os problemas ambientais, a EA transformou-se em uma das ferramentas para formação cidadã em prol da preservação ambiental e da participação coletiva nas ações que dizem respeito ao meio ambiente e busca de superação das injustiças sociais. Entretanto, para o desenvolvimento de uma prática transformadora, a EA deve estar respaldada em um novo paradigma, em que esteja comprometida com as questões sociais, pois a reprodução social caracterizada por injustiças e desigualdades está muitas vezes implícita em ações que favorecem a exclusão.

\section{Metodologia}

Nesse trabalho escolheu-se a pesquisa de abordagem qualitativa e optou-se pelo estudo de caso como um dos caminhos sistemáticos para explicação de fenômenos.

\section{Lócus da pesquisa}

Das oito escolas pertencentes ao Centro Educacional Carneiro Ribeiro (CECR) Escola Parque, a Escola Classe I, localizada no bairro do Pero Vaz, periferia do município de Salvador-BA, foi escolhida como lócus da pesquisa.

Dentre os motivos dessa escolha destacam-se os seguintes: a) há mais de duas décadas que a autora desse estudo atua como professora de Geografia; e b) a comunidade escolar que faz parte dessa instituição convive com problemas socioambientais (acúmulo de lixo, rede de esgoto exposta, problema de drenagem de água pluvial devido ao desgaste do asfalto).

\section{Abordagem da pesquisa}

Pedrini e Saito (2008) observam que, frente aos problemas socioambientais contemporâneos, o modelo atual de pesquisa exige a superação de uma visão cartesiana e mecanicista para uma visão sistêmica e ambiental.

Desse modo, e coerentemente com o objetivo geral da pesquisa, escolheu-se a pesquisa de abordagem qualitativa e, a fim de descrever as características da prática docente em EA, optou-se pelo estudo de caso como método. Segundo Prodanov e Freitas (2013), o 
estudo de caso é um tipo de pesquisa qualitativa e/ou quantitativa cujo objeto de estudo é uma unidade de forma aprofundada, podendo tratar-se de um sujeito, um grupo de pessoas ou uma comunidade. Além disso, de maneira complementar, usou-se a pesquisa documental cuja fonte foi o PPP da Escola Classe I - CECR, pois sua reformulação foi um dos objetivos do referido estudo.

Vale salientar que, por ser baseada em dados que não podem ser quantificados, a pesquisa qualitativa, conforme afirma Lima (2016), envolve tensões, pela multiplicidade de contradições e interpretações, por isso, é igualmente experiencial.

\section{Coleta de dados}

Recorreu-se como método de coleta de dados à entrevista semiestruturada, devido às vantagens mencionadas por Selltiz et al. (1987), como a de permitir maior entrosamento entre o pesquisador e os entrevistados, além de favorecer a abordagem de um tema complexo, a participação de professores de diferentes disciplinas e a flexibilidade na ordem das perguntas, de acordo com a dificuldade do entrevistado em respondê-las.

Após aprovação do projeto de pesquisa pelo Comitê de Ética as percepções docentes sobre EA foram informadas por meio de entrevistas realizadas com cinco professores dos anos finais da EJA da Escola Classe I das disciplinas da EJA: Geografia/Artes Laborais, Ciências Naturais, Língua Portuguesa/Inglesa, Matemática e História, pois a EA critica a compartimentalização do conhecimento por seu caráter interdisciplinar.

Entre os docentes do noturno, dez atuavam no ensino fundamental $\left(6^{\circ}\right.$ ao $9^{\circ}$ ano da EJA), sendo que cinco deles fizeram parte da amostra por atender aos seguintes critérios de inclusão: a) professores concursados, com mais de um ano de experiência; b) atuantes no ensino fundamental ( $6^{\circ}$ ao $9^{\circ}$ ano) na EJA, no turno noturno na Escola Classe I (CECR); c) atuantes em uma das disciplinas do currículo obrigatório.

\section{Análise e Discussão}

A EA é um tema transversal cuja relevância está igualmente ligada ao desenvolvimento da cidadania e à percepção de sujeito ativo no mundo frente aos problemas socioambientais prejudiciais à qualidade de vida. Nesse sentido, surgiu a problemática que deu origem a esse estudo: como os professores trabalhavam a EA com os estudantes do $6^{\circ}$ ao $9^{\circ}$ ano da modalidade EJA. 
A EA para a cidadania implica em ações que irão favorecer uma visão complexa do conhecimento em uma perspectiva de conexão entre os saberes da EA e deles com a vida. Assim, trabalhar a dupla função da EA - preservação do meio ambiente e equilíbrio das desigualdades sociais - é de extrema importância para os alunos da EJA, especificamente os da Escola Classe I, por pertencerem, em sua maioria, a uma comunidade que sofre com problemas socioambientais (moradias precárias, precário serviço de coleta de resíduos sólidos, rede de esgoto exposta, acúmulo de água pluvial decorrente de ruas com asfalto irregular e bueiros entupidos).

Apesar desse contexto, os dados coletados nas entrevistas concedidas pelos professores dos anos finais da EJA da Escola Classe I indicaram ausência de uma prática docente capaz de estimular a cidadania ambiental, visto que, a partir da fala dos entrevistados, os problemas socioambientais vivenciados cotidianamente pelos estudantes na comunidade da Liberdade, onde a Escola Classe I está inserida, não estavam sendo trabalhados de forma a levá-los, além da sensibilização sobre a necessidade da preservação ambiental, para participação cidadã em busca da qualidade de vida e equidade social com acesso à infraestrutura (rede de esgoto, água encanada, segurança, ruas asfaltadas, entre outros) por parte dos estudantes.

Nesse contexto, os docentes entrevistados trouxeram a questão do distanciamento entre os temas de EA abordados na referida escola e as próprias problemáticas enfrentadas na comunidade, expressando em suas falas um trabalho descontextualizado, pois os problemas socioambientais vividos pelas comunidades das quais os educandos fazem parte não eram relacionados aos fatores econômicos, sociais, históricos, éticos e políticos, de modo que os estudantes fossem estimulados ao exercício da cidadania, tornando-se atores capazes de transformar sua realidade.

Por meio das falas dos docentes entrevistados, percebeu-se a visão da EA como uma disciplina isolada e a falta de acesso ao PPP da Escola Classe I - CECR por parte da comunidade escolar. Assim, notou-se que a ausência da EA no PPP facilitava a dicotomia entre as diversas áreas do conhecimento na referida instituição escolar.

Nesse contexto, foi elaborado um anexo ao PPP para introdução da EA, possibilitando novas discussões sobre metas dessa área com os sujeitos da comunidade escolar e local em prol da formação cidadã e reflexões sobre os problemas socioambientais, principalmente os enfrentados pelos estudantes e estimular ações para amenização destes problemas. 
Além disso, a proposta do núcleo ou observatório no CECR-Escola Parque citada nesse trabalho não ficou apenas no projeto. Em fevereiro de 2019 foi inaugurado, na Escola Classe I, o Núcleo de EA e Artes (Neaaba), visando proporcionar o desenvolvimento de ações voltadas para aperfeiçoamento docente, socialização de conhecimentos em EA, troca de experiências entre a escola e a comunidade escolar e desenvolvimento da cidadania, principalmente por meio do Projeto Juventude em Ação em parceria com a Secretaria Estadual de Educação da Bahia.

\section{Referências}

BAHIA. Política Estadual de Educação Ambiental da Bahia. Lei nº 12.056/2011. Disponível em:

http://www.meioambiente.ba.gov.br/arquivos/File/Publicacoes/Livros/PoliticaEducacao Ambiental.pdf. Acesso em: 5 set. 2019.

CARVALHO, I. C. M. Educação ambiental: a formação do sujeito ecológico. 6. ed. São Paulo: Cortez, 2012.

COURE, M. L. M. O que é cidadania. São Paulo: Brasiliense, 2002. (Coleção Primeiros Passos).

FREIRE, P. Pedagogia do oprimido. 17. ed. Rio de Janeiro: Paz e Terra, 1987.

GRYNSZPAN, D. et al. Educação em saúde e educação ambiental: uma experiência inovadora com base em uma perspectiva socioambiental ligada à promoção da saúde. Enseñanza de las Ciencias, Barcelona, n. extra, p. 1.668-1.673, 2013.

JACOBI, P. Educação ambiental, cidadania e sustentabilidade. Cadernos de Pesquisa, São Paulo, n. 118, p. 189-205, mar. 2003. Doi: 10.1590/S0100-15742003000100008.

LAYRARGUES, P. P.; LOUREIRO, C. F. B.; CASTRO, R. S. Repensar a educação ambiental: um olhar crítico. São Paulo: Cortez, 2009.

LIMA, T. P. P. Entrelaçando saberes e práticas: a história ensinada no $5^{\circ}$ ano do Ensino Fundamental na cidade do Salvador/BA. 2016. 303 f. Tese (Doutorado em Educação) Faculdade de Educação, Universidade Federal da Bahia, Salvador, 2016.

MORIN, E. Os sete saberes necessários à educação do futuro. São Paulo: Cortez, 2011.

PAPANI, S. Vigilância em saúde ambiental: uma nova área ecológica. 2. ed. São Paulo: Atheneu, 2012.

PEDRINI, A. G.; SAITO, C. Paradigmas metodológicos em educação ambiental. Petrópolis, RJ: Vozes, 2014. 
PRODANOV, C. C.; FREITAS, E. C. Metodologia do trabalho científico: métodos e técnicas da pesquisa e do trabalho acadêmico. 2. ed. Novo Hamburgo: Feevale, 2013.

SELLTIZ, C. et al. Métodos de pesquisa nas relações sociais. Tradução de Maria Martha Hubner de Oliveira. 2. ed. São Paulo: EPU, 1987.

SERPA, A.; SANTOS, J. L. J. A produção espacial do comércio e dos serviços nas periferias urbanas. GEOUSP Espaço e Tempo [on-line], São Paulo, v. 4, n. 2, p. 45-65, 2000. Doi: 10.11606/issn.2179-0892.geousp.2000.123481.

UNESCO. Relatório de monitoramento global de Educação Para Todos Brasil 2005: o imperativo da qualidade. São Paulo: Moderna, 2005. Disponível em: http://unesdoc.unesco.org/images/0013/001390/139079por.pdf. Acesso em: 21 set. 2018.

VALLA, V.; STOTZ, E. Educação, saúde e cidadania. Petrópolis-RJ: Vozes, 1994.

WALDMAN, M. Cidadania ambiental: natureza e sociedade como espaço para cidadania. In: PINSKY, J.; PINSKY, C. B. (org.). História da cidadania. São Paulo: Contexto, 2003. p. 545-561.

Submetido em 29 de fevereiro Aprovado em 8 de abril de 2020. 